Bol. Acad. peru. leng. 47. 2009 (139-142)

\title{
HOMENAJE POR EL NONAGÉSIMO DEL NATALICIO DEL DR. FRANCISCO MIRÓ QUESADA CANTUARIAS
}

\author{
María Luisa Rivara de Tuesta \\ Universidad Nacional Mayor de San Marcos
}

Sr. Presidente de la República, Dr. Alan García Pérez

Sr. Embajador Javier Pérez de Cuéllar

Presidente del Comité de Honor de la Comisión de Homenaje al Dr. Francisco Miró Quesada Cantuarias

Sr. José Antonio García Miró Miró Quesada

Presidente del Directorio de la Empresa Editora El Comercio

Señores integrantes de la mesa de honor

Sr. Dr. Francisco Miró Quesada Cantuarias

Sr. Dr. Francisco Miró Quesada Rada

Señoras y señores

El Museo Pedro de Osma, un espacio con su propia historia de preservación de arte colonial y artesanía popular, es el que nos acoge para la realización de esta ceremonia de Homenaje al Dr. Francisco Miró Quesada Cantuarias, con motivo de su onomástico y por la presentación de una nueva publicación: una antología de sus artículos periodísticos.

Sus Filosofemas, que se publican cada semana y que llegan al gran público son reflexiones para hacernos pensar o meditar sobre sucesos 
y circunstancias que conciernen a nuestra vida colectiva o a la vida de cada persona en particular. En cada uno de sus artículos está implícita su vocación de filósofo humanista, racionalista, y sobre todo, su magisterio de educador.

La vida y obra de Francisco Miró Quesada Cantuarias dedicada a la filosofía, es de una coherencia admirable, tanto en lo que concierne a su vida personal como a su obra intelectual de consistencia racionalista irrefutable y de plenitud humanista.

Lo aprecié como maestro de Lógica Superior en el año 1962 en la Universidad Nacional Mayor de San Marcos, he seguido su obra monumental que ha podido realizar porque se fue ejecutando desde un proyecto existencial que partió de la idea de dedicar su vida a la difícil pero imperiosa necesidad interior de ser auténtico filósofo, es decir, dedicar su vida a la tarea de seguir dictámenes de su razón, que se ha ido desarrollando metódica y dialécticamente entre: "el aprender y enseñar lo aprendido".

Al estudiar aprende, al transmitir lo aprendido enseña, pero al enseñar se le apertura una nueva problemática que debe resolver a través de nuevos estudios e investigaciones, se le abre en esta forma un constante abanico de perspectivas de nuevos análisis que una vez realizados amplían sus horizontes de conocimiento, que plasma sistemáticamente en escritos que expone en la cátedra, congresos, coloquios y reuniones científicas, pero, paralelamente atiende a su difusión o divulgación, con especial interés y cuidado pedagógico, en textos escolares, ponencias, folletos y artículos periodísticos.

La Sociedad Peruana de Filosofía, con acta de constitución del 9 de octubre de 1940, y siendo su primer presidente el Dr. Víctor Andrés Belaunde, es donde inicia su importante participación como su primer Secretario general. Su inauguración el 16 de mayo de 1941, tal como dieron cuenta los diarios de la época, destacan sobre todo el discurso del Secretario, Dr. Francisco Miró Quesada, y del Presidente, Dr. 
Víctor Andrés Belaunde que expuso un esbozo de su teoría sobre "La síntesis viviente”. Desde esa memorable inauguración hasta el presente, sus enseñanzas y su manejo impecable en los debates, su comprensión humana y su respeto a las ideas de los nuevos socios, reflejan no solo su constante dedicación a la Institución, sino que a través de sus ponencias e investigaciones, que constan en las publicaciones de los Archivos de la Sociedad, los tomos VI, VII y VIII, siempre ha alentado el quehacer filosófico de nuestros miembros activos. Los Archivos se han podido gestar gracias a su comprensiva apertura y atención respetuosa, no sólo para los ponentes, sino también para nuestros posibles socios a quienes, durante las sesiones, ha dado la oportunidad de asistir, e incluso, participar en los debates y expresar sus opiniones con entera libertad.

La idea directriz que despliega la magna obra escrita de Francisco Miró Quesada parte de sus estudios profesionales de Filosofía, Matemáticas y Derecho y de las tesis elaboradas para obtener los grados académicos respectivos las temáticas abarcan las especialidades de: Filosofía, Matemáticas, Lógica, Lógica Jurídica, Filosofía de la ciencia, Filosofía humanista, Moral y Ética, Lingüística, Planificación y Educación.

A Francisco Miró Quesada en este justo homenaje a su brillante trayectoria como hombre cabal y como arquetipo de intelectual peruano, quiero agradecerle personalmente sus enseñanzas y su amistad, como hombre cabal porque al hallarse en esta tempo-espacialidad, o Pachamama, en la que le tocó nacer, ha ido comprendiendo y realizando su existencia reconociendo su enraizamiento con la cultura milenaria que se desarrolló en esta parte del continente, y con la cultura occidental superpuesta y transplantada con motivo de la penetración española, de la que él ha asumido sus valores filosóficos humanistas. Hombre cabal como hijo vinculado profunda y entrañablemente con Racso, su padre y maestro, igualmente, con su familia fundada hace más de cincuenta años en existencia solidaria con Doris Rada, compañera tierna y a quien, creo poder designar como la joya más preciada de nuestro maestro y amigo, a sus hijos por la dedicación y amor con que han contribuido a este acto de reconocimiento; y hombre cabal como arquetipo de intelectual que 
ha desplegado su reflexión filosófica teniendo, sin embargo, muy en cuenta la realidad de Hispanoamérica y de nuestro país, insertos en la dominación y el subdesarrollo.

Muchas gracias

Lima, 19 de diciembre de 2008. 